\title{
EDUCAÇÃO PROFISSIONAL E TECNOLOGICA (EPT) NO BRASIL E SEUS \\ DOCENTES: TRAJETOS E DESAFIOS
}

\section{PROFESSIONAL AND TECHNOLOGICAL EDUCATION IN BRAZIL AND ITS TEACHERS: TRAJECTS AND CHALLENGES}

\author{
Guilherme da Silva dos Santos \\ Mestre em Letras pela Universidade Federal de Santa Maria \\ Professor do Instituto Federal Farroupilha \\ Pesquisador do Centro de Ensino e Pesquisa em Línguas Instrumentais (UFSM) \\ E-mail: santos.sm@hotmail.com \\ Maria Tereza Nunes Marchesan \\ Pós-doutora pela Texas A\&M University \\ Doutora em Letras pela Universidade federal do Rio Grande do Sul \\ Professora Associada da Universidade Federal de Santa Maria \\ E-mail: ttmarchesan@gmail.comia
}

\section{RESUMO}

$\mathrm{Na}$ data de 29 de dezembro do ano de 2008 foi sancionada a Lei $\mathrm{n}^{\circ} 11.892$, criando os Institutos Federais de Educação, Ciência e Tecnologia (IFET) com o propósito de fundar a igualdade na diversidade social, econômica, geográfica e cultural do Brasil. Nesse contexto, a função do professor, atuante nessa modalidade de ensino, começou a receber maiores atenções. Dessa forma, visando a contribuir com as investigações nessa modalidade de ensino brasileiro, o objetivo deste trabalho é apresentar a trajetória da Educação Profissional e Tecnológica (EPT) no Brasil, assim como registrar as mudanças contextuais que a EPT apresentou no país com base na formação de seus professores. Para esta investigação, realizou-se um resgate histórico na cronologia da EPT e a qualificação dos docentes em exercício nessa modalidade, para assim, contrastar com a EPT e a qualificação docente atual. Foi possível perceber que de "um forte contingente de profissionais de áreas diversas, sem a qualificação pedagógica” (PEREIRA, 2004, p.03), a EPT brasileira, a partir da LDB e a Lei $n^{\circ}$ 5.692/61, vem procurando estabelecer debates sobre a atuação do docente em serviço nessa modalidade.

Palavras-chave: Formação de Professores. Educação Profissional e Tecnológica. Desafios Docentes.

\section{ABSTRACT}

On December 29, 2008, the Law 11.892 was passed, creating the Federal Institutes of Education, Science and Technology (FIEST) with the purpose of founding equality in the social, economic, geographic and cultural diversity of Brazil. In this context, the role of the teacher, active in this 
type of teaching, began to receive more attention. Thus, in order to contribute to research in this Brazilian teaching modality, the objective of this work is to present the trajectory of Professional and Technological Education (PTE) in Brazil, as well as to record the contextual changes that the PTE presented in the country based on the training of their teachers. For this investigation, a historical rescue in the chronology of the PTE and the qualification of the teachers in exercise in this modality were carried out, in order to contrast with the PTE and the current teaching qualification. It was possible to perceive that from "a strong contingent of professionals from different areas, without pedagogical qualification (PEREIRA, to establish debates about the actuation of the teacher that teaches in this modality.2004, p. 03)", the Brazilian PTE, based on LDB and on Law 5.692/61, has been trying

Key-words: Teacher Training. Professional and Technological Education. Teaching Challenges.

\section{INTRODUÇÃO}

A partir do momento em que a Lei $\mathrm{n}^{0} 11.892$ foi sancionada em 29 de dezembro do ano de 2008 criando 38 Institutos Federais de Educação, Ciência e Tecnologia (IFET) no Brasil, olhares mais atentos foram voltados para a temática da formação do docente da educação profissional e tecnológica (EPT) brasileira. Com a criação dos IFET’s, surge, também, uma nova (ou nem tanto assim) perspectiva do serviço docente para o exercício na modalidade da EPT. Nesse cenário, é de suma importância fomentar discussões que sinalizem temáticas de políticas públicas de formações de professores para a docência na EPT, pois, problematizar questões envolvendo o processo de formação do professor para a EPT tem mobilizado grandes debates acadêmicos e políticos na área educacional (CARVALHO e SOUZA, 2014).

Tendo em vista o objetivo de contribuir com a questão acadêmica da formação de professores para o serviço na EPT brasileira, este trabalho desenvolveu, em um primeiro momento, um apanhado cronológico sobre o registro histórico da EPT desde sua origem até dias atuais. Esse foco na pesquisa cronológica da modalidade de ensino da EPT serviu para resgatar o espaço que o professor desempenhou suas atividades de ensino. Esses dados obtidos através do resgate histórico possibilitam contrastar com a realidade docente na EPT atual. Por fim, esta investigação apresenta reflexões acerca da formação do professor para o serviço na EPT, para assim, fomentar melhores bases de discussões sobre esta temática no espaço da educação brasileira. 


\section{PERCURSO HISTÓRICO SOBRE A EDUCAÇÃO PROFISSIONAL E TECNOLÓGICA (EPT) NO BRASIL}

O histórico da Educação Profissional e Tecnológica no Brasil (EPT) data do início do século XIX com o objetivo de profissionalizar jovens, filhos da classe proletária, desprovidos de recursos financeiros (MAGALHÃES, 2011). Ainda, segundo a autora, tal iniciativa brasileira de formar mão-de-obra:

ocorreu por decorrência do pensamento europeu proveniente do século XIX, segundo o qual, a sociedade se constituía de duas classes sociais opostas: burgueses e trabalhadores, que possuíam papéis diferentes e para os quais a escola deveria ser organizada de maneira particular. Nesse sentido, às classes de poder aquisitivo considerável eram reservados os estudos clássicos, o trabalho intelectual era valorizado às elites; às classes menos favorecidas cabia o trabalho manual, menos valorizado. Sacramentava-se, assim, a velha dualidade do ensino: uma escola para os pobres e uma escola para os ricos; uma escola para aqueles que vão dirigir a sociedade e uma escola para aqueles que vão servir a sociedade. (MAGALHÃES, 2011, p.93)

Seguindo o percurso histórico da EPT no Brasil, Pacheco (2012), apresenta o ano de 1909 como um marco pontual, pois, foi quando Nilo Peçanha, ao assumir a Presidência da República, por intermédio do Decreto $\mathrm{n}^{\circ}$. 7.566, de 23 de setembro de 1909, inaugurou, nas capitais dos Estados brasileiros, dezenove Escolas de Aprendizes Artífices.

Segundo Oliveira Junior (2008), estas escolas foram criadas com o objetivo de oferecer ensino profissional gratuito para qualificar uma mão-de-obra que soubesse produzir de acordo com a demanda produtiva de cada região do País, uma vez que cada local possuía cursos de acordo com as suas necessidades latentes de trabalho.

Complementando esse dado, Kunze (2009) expõe que,

[...] a criação da rede federal de educação profissional no Brasil [...] ocorreu no final da década de 1910, quando o governo federal criou e instalou em cada capital brasileira uma Escola de Aprendizes Artífices, com a finalidade de ministrar o ensino de ofícios referentes às especialidades industriais de cada Estado, proporcionar aos considerados ociosos e desprovidos da fortuna uma profissão, um ofício, e formar os futuros operários úteis às indústrias nascentes. $\mathrm{O}$ conjunto das dezenove escolas profissionais congêneres foi concebido no âmbito das ações voltadas à afirmação e consolidação da República Federativa Brasileira, bem como, ao seu progresso que foi atribuído à educação do povo, ao controle social e à industrialização, entre outras condições (KUNZE, 2009, p. 9).

Para Kunze (2009), a razão de oferecer ao povo, que se aglomerava nas cidades, uma profissão, uma ocupação/ofício por meio do ensino profissional era a geração de maiores incentivos ao trabalho e mão-de-obra as indústrias que começavam a surgir no País, devido às mudanças que vinham ocorrendo na economia agrário-exportadora. Para a autora, o público alvo 
deste ensino era o considerado desprovido da riqueza e que, por conseguinte, estava à margem da sociedade e desvinculado dos setores produtivos, engrossando um grupo urbano periférico que atrapalhava o desenvolvimento do País.

Neste contexto, Borges (2013) expõe que no dado momento histórico, para a administração federal, a educação dessa população era considerada um dos caminhos que levariam ao progresso do Brasil, sendo que possibilitaria crescimento ordenado da vida urbana, sem proliferação de ideias contrárias ao do governo.

Assim, Kunze (2009) apresenta que com tais propósitos, a instalação dessa rede escolar foi o marco inicial do processo de escolarização do ensino profissional no regime republicano e significou a efetivação da primeira política nacional dessa modalidade de ensino.

Foi no ano de 1937, conforme apresenta BRASIL (2011), que a educação técnica passou a ser vista como um elemento estratégico para o desenvolvimento social e econômico da classe trabalhadora pois, a Constituição promulgada pelo presidente Getúlio Vargas transformou as Escolas de Aprendizes e Artífices em Liceus Industriais.

Os Liceus passaram a trabalhar em sintonia com a expansão da indústria, que então passara a se desenvolver mais rapidamente. Para sustentar esse crescimento, era preciso formar mão de obra qualificada, um bem escasso no Brasil naquele momento" (BRASIL, 2011, s/p).

No ano de 1942, Gustavo Capanema, então ministro da Educação e Saúde no Brasil, promove uma grande mudança na estrutura educacional brasileira onde equiparou o ensino profissionalizante e técnico ao nível médio e os Liceus passaram a ser chamados de Escolas Industriais e Técnicas (EIT’s) (BRASIL, 2011).

Neto (2009) advoga que na década de 1940, com a intensificação da industrialização (com forte apoio do Estado), as Escolas Industriais acompanharam o novo modelo de desenvolvimento, qualificando mão-de-obra, tendo em vista o seu papel estratégico para o País, principalmente na formação das áreas de infraestrutura para o desenvolvimento econômico das décadas seguintes.

O modelo educacional proposto por Gustavo Capanema perdurou até o ano de 1959 quando as EIT's foram transformadas em Escolas Técnicas Federais (ETF's) passando a adquirirem autonomia pedagógica e administrativa (BRASIL, 2011).

\footnotetext{
Pouco depois, o ensino técnico ganhou um novo status. A fixação por lei das Diretrizes e Bases da Educação Nacional, em 1961, equiparou o ensino profissional ao ensino acadêmico. Até então, prevalecia a ideia de que esse tipo de formação era destinada apenas a indivíduos carentes - os mesmos "desafortunados" da época de Nilo Peçanha. A partir desse momento, o ensino profissional e técnico passou a ser considerado essencial para a expansão da economia e passou a se basear nas escolas técnicas dos países industrializados. (BRASIL, 2011, s/p)
} 
Assim, chega-se aos anos 70, especificamente, ano de 1971 sob o governo regime militar. Este, instaurou uma profunda mudança na ordem na educação básica brasileira, pois, ocorreu a promulgação da Lei 5.692/71, Lei da Reforma do Ensino de $1^{\circ}$ e $2^{\circ}$ Graus, que instaurava a profissionalização compulsória em todo o Brasil, fazendo com que todos os cursos de $2^{\circ}$ grau passassem a ter caráter profissionalizante (MAGALHÃES, 2011). Assim, com a crescente aceleração da economia brasileira dos anos 70 , houve uma grande procura pelo ensino técnico e profissionalizante e, no ano de 1978, surgiram os três primeiros Centros Federais de Educação Tecnológica (Cefets), centralizados nas Escolas Técnicas Federais de Minas Gerais, do Paraná, do Rio de Janeiro, que tinham como objetivo formar engenheiros de operação e tecnólogos (BRASIL, 2011).

Ainda nesse sentido, Brasil (2011, s/p) expõe que

os Cefets viraram a unidade padrão da Rede Federal de Ensino Profissional, Científico e Tecnológico. Eles absorveram as atividades das ETFs e das Escolas Agrotécnicas Federais e se preocuparam em preparar o País para a revolução tecnológica ocorrida entre os anos 1980 e 1990.

Nesse espaço cronológico, o ano de 1996 registra uma mudança significativa no que tange o ensino profissional técnico. Com a promulgação da Lei de Diretrizes e Bases da Educação Nacional - LDB nº 9.394/96 favoreceu a publicação do Decreto Lei $n^{\circ}$ 2.208/96, reformulando o ensino técnico, promovendo a separação das disciplinas de formação geral daquelas destinadas à formação técnico-profissional (MAGALHÃES, 2011).

Em 2004, por determinação do Decreto 5.154/04, foi reintegrado, mais uma vez, o ensino técnico ao médio e, em 2005, o Decreto 5.458/05 criou o Programa de Integração da Educação Profissional Técnica de Nível Médio ao Ensino Médio na Modalidade Educação de Jovens e Adultos - PROEJA (MAGALHÃES, 2011, p.96)

Em 29 de dezembro de 2008, o presidente Luiz Inácio Lula da Silva sancionou a Lei ${ }^{\circ}$ 11.892/08, que criou 38 Institutos Federais de Educação, Ciência e Tecnologia (IFET), publicada no Diário Oficial da União de 30 de dezembro do mesmo ano, com o objetivo de se comprometer com a sociedade para fundar a igualdade na diversidade social, econômica, geográfica e cultural brasileiro. (BORGES, 2013).

Recentemente, com a Lei ${ }^{\circ} 12.513$ de 26 de outubro do ano de 2011, sob o governo da Presidenta Dilma Rousseff, institui-se o Programa Nacional de Acesso ao Ensino Técnico e Emprego (Pronatec); o qual foi criado com o objetivo de

I expandir, interiorizar e democratizar a oferta de cursos de educação profissional técnica de nível médio presencial e a distância e de cursos e programas de formação inicial e continuada ou qualificação profissional;

II fomentar e apoiar a expansão da rede física de atendimento da educação profissional e tecnológica; 
III contribuir para a melhoria da qualidade do ensino médio público, por meio da articulação com a educação profissional;

IV ampliar as oportunidades educacionais dos trabalhadores, por meio do incremento da formação e qualificação profissional;

$\mathrm{V}$ estimular a difusão de recursos pedagógicos para apoiar a oferta de cursos de educação profissional e tecnológica.

VI estimular a articulação entre a política de educação profissional e tecnológica e as políticas de geração de trabalho, emprego e renda. (Incluído pela Lei ${ }^{\circ}{ }^{\circ} 12.816$, de 2013) (BRASIL, 2013, p.01).

Dessa forma, é possível perceber que a EPT brasileira sofreu - e vem sofrendo significativas mudanças ao longo de seu trajeto temporal. Mudanças, essas, que refletem as necessidades de melhorias no meio em que a sociedade está vinculada.

Com o objetivo de demonstrar, em uma linha cronológica, uma síntese do histórico da EPT no Brasil desde seu surgimento até tempos de hoje, apresenta-se o seguinte quadro:

\section{Quadro 01 - síntese do histórico da EPT no Brasil.}

\begin{tabular}{|c|c|}
\hline ANo & NAL NO BRASIL \\
\hline 1909 & $\begin{array}{l}\text { O Decreto-Lei } \mathrm{n}^{0} 7.5662 \text {, de } 23 \text { de setembro de } 1909 \text {, sancionado pelo Presidente da República Nilo } \\
\text { Peçanha, instituiu oficialmente a educação profissional no Brasil, com a criação de } 19 \text { Escolas de } \\
\text { Aprendizes Artífices que objetivava a preparação de mão de obra qualificada. }\end{array}$ \\
\hline 1937 & $\begin{array}{l}\text { educação técnica passou a ser vista como um elemento estratégico para o desenvolvimento social e } \\
\text { nômico da classe trabalhadora pois, a Constituição promulgada pelo presidente Getúlio Vargas } \\
\text { sfformou as Escolas de Aprendizes e Artífices em Liceus Industriais. }\end{array}$ \\
\hline 1940 & grande industrialização no Brasil. \\
\hline 1942 & $\begin{array}{l}\text { Saúde no Brasil, promove uma grande mudança na } \\
\text { ssino profissionalizante e técnico ao nível médio e os } \\
\text { ais e Técnicas (EIT's). }\end{array}$ \\
\hline 1959 & las em Escolas Técnicas Federais (ETF's) passando a adquirirem autonomia \\
\hline 1971 & $\begin{array}{l}\text { nulgação da Lei } 5.692 / 71 \text {, Lei da Reforma do Ensino de } 1^{\circ} \text { e } 2^{\circ} \text { Graus, que instaurava a } \\
\text { issionalização compulsória em todo o Brasil, fazendo com que todos os cursos de } 2^{\circ} \text { grau passassem a } \\
\text { aráter profissionalizante. }\end{array}$ \\
\hline 1978 & $\begin{array}{l}\text { ros Federais de Educação Tecnológica (Cefet's), centralizados nas Escolas } \\
\text { Gerais, do Paraná, do Rio de Janeiro, que tinham como objetivo formar } \\
\text { ólogos }\end{array}$ \\
\hline $\begin{array}{l}1980 \\
1990\end{array}$ & $\begin{array}{l}\text { eríodo em que os Cefet's viraram a unidade padrão da Rede Federal de Ensino Profissional, Científico e } \\
\text { 'ecnológico. Eles absorveram as atividades das ETF's e das Escolas Agrotécnicas Federais e se } \\
\text { reocuparam em preparar o País para a revolução tecnológica ocorrida entre os anos } 1980 \text { e } 1990 \text {. }\end{array}$ \\
\hline 1996 & $\begin{array}{l}\text { - LDB } \mathrm{n}^{\circ} 9.394 / 96 \text {, a qual favoreceu a } \\
\text { técnico, promovendo a separação das } \\
\text { ico-profissional. }\end{array}$ \\
\hline 200 & \\
\hline 2005 & $\begin{array}{l}\text { ssional Técnica de Nível Médio ao } \\
\text { A. }\end{array}$ \\
\hline 2008 & $\begin{array}{l}\text { O Presidente da República Luiz Inácio Lula da Silva sanciona a Lei nº 11.892/08, criando } 38 \text { Institutos } \\
\text { Federais de Educacão, Ciência e Tecnologia (IFET). }\end{array}$ \\
\hline 2011 & $\begin{array}{l}\text { da Presidenta Dilma Rou } \\
\text { (Pronatec). }\end{array}$ \\
\hline
\end{tabular}

Fonte: Dados da Pesquisa 
Após esse percurso cronológico apresentado nessa pesquisa (e sintetizado no Quadro 01) sobre a EPT no Brasil, é possível perceber que esta modalidade de ensino possui um caráter ascendente na esfera educacional brasileira, isto é, percebe-se um crescimento na importância dessa modalidade de ensino nas políticas educacionais brasileira. Reconhecendo a necessidade de preparar uma geração apta a operacionalizar frente às exigências de um mercado de trabalho cada vez mais competitivo, o papel do professor se reveste de grande importância no contexto da EPT, visto que, parte do sucesso posterior do discente no campo laboral, dependerá das lições transmitidas por seus professores.

Nesse sentido, a próxima sessão apresentará reflexões acerca da formação do professor para o serviço na EPT, para assim, fomentar melhores bases de discussões sobre esta temática no espaço da educação brasileira.

\section{A FORMAÇÃO DE PROFESSORES PARA O SERVIÇO NA EPT}

Abordar temas de pesquisas que abarquem problematizações envolvendo a formação do professor tem sido objeto de pesquisas contínuas (CELANI, 2008) cada vez mais frequentes, abordando não apenas a questão da formação inicial do docente, como também, questões envolvendo o professor em fase de estabilização didático-profissional (NONO, 2011) e, também, os dilemas e desafios da formação continuada desses docentes, pois, a formação de um professor não cessa após ele ter seu diploma em mãos. A formação do docente é um processo dinâmico e jamais estático (IMBERNÓN, 2011).

Nesse universo, um outro tipo de formação docente apresenta pontos de reflexão e discussão desde meados dos anos 90 do século XX: a formação do professor para a EPT pois, de acordo com Abreu (2009), a última década do século passado o Brasil, atrelado ao mundo da globalização social, econômica e tecnológica, aderiu às exigências do cenário complexo e produtivo em que estava inserido e, assim, passou a incentivar mais a formação técnica para o mercado de trabalho.

Nesse sentido, em 20 de dezembro do ano de 1996, foi aprovada a segunda Lei de Diretrizes e Bases da Educação Nacional, a LDB n 9.394/96, em seu Título V, que trata "dos níveis e das modalidades de educação e ensino", aborda em seu Capítulo III sobre a Educação Profissional. Nesse capítulo, em suma, o texto defende uma educação nacional voltada ao mundo do trabalho, a qual se preocupa em desenvolver sujeitos que, além de possuírem uma capacidade crítico-social, sejam capazes de desempenhar condições para atuar no mercado de trabalho (ABREU, 2009). 
Logo, nesse ensejo que marca tal preocupação com a educação brasileira, um ator desponta no cenário voltado ao mundo do trabalho: o professor. Porém, esse surgir que caracteriza o docente dessa modalidade de ensino nacional não se apresenta com elogios e aplausos, mas sim, com uma dúvida: qual a formação que a universidade oportuniza ao professor para a sua atuação na modalidade do ensino profissional técnico brasileiro?

Nesse sentido, antes de buscar respostas para essa inquietação, necessário se faz conhecer o processo de inclusão que os professores tiveram na modalidade de ensino profissional brasileira. Assim, é possível concatenar melhor as possíveis respostas que forem obtidas sobre o processo de formação do professor atuante na modalidade da educação profissional.

É imperativo o papel social que desempenha um professor para formar cidadãos qualificados para o exercício de suas atribuições profissionais no mercado de trabalho. Entretanto, para que esse docente seja capaz de abordar questões profícuas na formação de um cidadão, deve-se reconhecer que ele próprio deva possuir uma formação de qualidade.

Atualmente, no Brasil, há um discurso em prol de uma educação profissional, a qual possibilite ao aluno um ensino técnico voltado ao trabalho em diferentes áreas produtivas (ABREU, 2009). Nesse cenário, espera-se que esse aluno seja proficiente em uma determinada área técnica do mundo do trabalho, a partir dos ensinamentos transmitidos pelo professor (sejam eles teóricos ou práticos).

Porém, voltamos a uma afirmativa recentemente posta em evidência: para que esse docente seja capaz de abordar questões profícuas na formação de um cidadão, deve-se reconhecer que ele próprio deva possuir uma formação de qualidade. Logo, como pode-se tratar a questão da formação do professor atuante na modalidade do ensino profissional brasileiro?

Retomando subsídios cronológicos sobre esse tema, Pereira (2004) expõe um dado curioso na perspectiva docente na modalidade de ensino técnico profissionalizante. Segundo o autor, por muito tempo o ensino técnico no Brasil foi marcado por "um forte contingente de profissionais de áreas diversas, sem a qualificação pedagógica (PEREIRA, 2004, p.03) ”.

Conforme apresenta Oliveira Junior (2008), o assunto formação de professores para a EPT teve origem no ano de 1961, com o advento da LDB e a Lei $n^{0} 5.692 / 61$, pois, foi a Lei que mencionou que a EPT passaria a tornar-se parte do currículo do segundo grau. Assim, de acordo com Oliveira Junior (2008), a LDB de 1961 apresentava que o docente em serviço de ensino técnico deveria ter formação específica, através de cursos especiais de formação técnica.

No ano de 1978, em 30 de junho, no governo Ernesto Geisel, o tema da formação de professores para a atuação no EPT fica a cargo dos Centros Federais de Educação Tecnológica (CEFET's) a partir da Lei no 6.545 (PEREIRA, 2004). 
No artigo $2^{\circ}$ da referida lei, encontra-se

Art. $2^{\circ}$ Os Centros Federais de Educação Tecnológica de que trata o artigo anterior têm por finalidade o oferecimento de educação tecnológica e por objetivos:

I ministrar em grau superior:

a) de graduação e pós-graduação lato sensu e stricto sensu, visando à formação de profissionais e especialistas na área tecnológica;

b) de licenciatura com vistas à formação de professores especializados para as disciplinas específicas do ensino técnico e tecnológico;

II ministrar cursos técnicos, em nível de $2^{\circ}$ grau, visando à formação de técnicos, instrutores e auxiliares de nível médio;

III ministrar cursos de educação continuada visando à atualização e ao aperfeiçoamento de profissionais na área tecnológica;

IV realizar pesquisas aplicadas na área tecnológica, estimulando atividades criadoras e estendendo seus benefícios à comunidade mediante cursos e serviços (BRASIL, 1993, s/p. Grifos do autor).

Essa atualização profissional para a área técnica, segundo Oliveira Junior (2008), era realizada por meio dos Esquemas I e II, que, explica Pereira (2004), eram cursos de capacitação docente tidos como emergências. O Esquema I era uma complementação pedagógica para os professores de nível superior e o Esquema II representava uma capacitação para docentes com formação técnica de nível médio (OLIVEIRA JUNIOR, 2008).

Naquele tempo, conforme complementa Pereira (2009, p.04),

a expansão do parque industrial brasileiro acendera a exigência de alteração na formação de profissionais, dando-se peso à questão do domínio de tecnologias mais avançadas por parte dos técnicos, daí a ênfase na formação de professores para essas disciplinas.

Por fim, a formação do professor para a EPT foi regulamentada por meio do artigo $8^{\circ}$ do Decreto 2.406/97, o qual passou a vigorar com a seguinte redação em 27 de novembro de 1997:

Art. $8^{\circ}$ - Os Centros Federais de Educação Tecnológica, transformados na forma do disposto no art. $3^{\circ}$ da Lei $n^{\circ} 8.948$, de 1994, gozarão de autonomia para a criação de cursos e ampliação de vagas nos níveis básico, técnico e tecnológico da Educação Profissional, bem como para implantação de cursos de formação de professores para as disciplinas científicas e tecnológicas do Ensino Médio e da Educação Profissional. (Grifos do autor)

No entanto, esclarece Oliveira Junior (2008), este Decreto foi revogado no ano de 2004 e substituído pelo Decreto 5154/04, o qual não trata da exigência de formação pedagógica do professor do ensino técnico e no ano de 2007, com o Decreto 6095/07, há a transformação das escolas de Aprendizes Artífices em Instituições de Educação Profissional e Tecnológica IFET's, trazendo também o Programa Especial de Formação Pedagógica, o qual possui o objetivo de capacitar bacharéis para o exercício da docência. 
Esse Programa Especial de Formação Pedagógica visa atender ao $§ 4^{\circ}$ do Art. 87 da Lei Federal 9394/96 e ao Parecer CNE/CP 07/2009, que determinava que os professores do ensino técnico e tecnológico fossem habilitados em nível superior (Licenciaturas) ou formados por treinamento em serviço (o curso objetiva capacitar os profissionais - bacharéis e tecnólogos para serem docentes na sua área de atuação nos cursos técnicos e tecnológico). Dessa forma, tais docentes buscaram essa formação em cursos de espacialização Lato Sensu por instituições capacitadas ou por programas especiais de graduação, ofertados por universidades. Em ambos os casos, o objetivo era formar professores capacitados, em nível superior, para a docência na modalidade da EPT.

No entanto, essa determinação registrada anteriormente no Art. 87 da Lei Federal 9394/96 e ao Parecer CNE/CP 07/2009, no ano de 2013, foi revogada pela Lei $n^{\circ} 12.796$. Dessa forma, a exigência para que o docente em serviço na EPT tivesse a formação acima exigida, com tal revogação, torna-se não-obrigatória.

Retomando o início da história da EPT e a formação dos docentes para o serviço nessa modalidade do ensino, marcado, inicialmente pela ação de professores leigos no assunto e, posteriormente, registrando a preocupação em mudar a realidade que se apresentava, observa-se a preocupação no interesse em capacitar docentes hábeis a atuarem, também, na EPT.

Sobre esse assunto, Oliveira Junior (2008 p.72) aponta que:

Um dos maiores problemas relacionado com a formação de professores em geral e que ficou mais evidenciado nas tentativas de formação de professores para o ensino técnico é que as Universidades têm dificuldades intrínsecas para lidar com essa questão. Nas licenciaturas o que se ensina basicamente é a História da Educação [...] poucas vezes se discute o aqui e o agora. Poucas vezes se discute o real e o concreto, a escola da realidade e o que o professor irá encontrar.

Assim, registra-se o papel importante que incumbe às Universidades no tocante a formação dos professores. De acordo com Valezi e Cox (2011), o docente que se depara com a missão de atuar em contexto de EPT, muitas vezes, enfrenta uma forte inquietação: como ser professor na educação profissional?

Essa dúvida é devida a formação do professor que desde o início do curso de licenciatura foi orientado a atuar em escolas de ensino fundamental e médio. Nesse prisma "os professores sentem-se desafiados a reorganizar suas práticas pedagógicas para atender efetivamente às novas demandas de aprendizagem nos cursos de formação profissional" (VALEZI, 2009 p.200) uma vez que durante a formação universitária não houve um momento didático voltado para essa modalidade do ensino. 
Nessa perspectiva, Pereira (2004, p.04) menciona que

O cenário atual da educação brasileira aponta para uma estruturação curricular que articule teoria e prática, o científico e o tecnológico, com conhecimentos que possibilitem ao aluno atuar no mundo produtivo em constante mudança, buscando a autonomia e desenvolvendo o espírito crítico e investigativo.

Corroborando com esta constatação, Carvalho e Souza (2014, p. 887), defendem a necessidade de "avançar para uma epistemologia da formação com bases na concepção de práxis, que propicia a articulação dialética entre a prática social e seus fundamentos teóricos $[\ldots]^{\prime}$.

Por fim, analisando a história da EPT no Brasil, a qual iniciou com uma política de ensino destinado a classe menos favorecida do País e alavancou em uma oportunidade de formação profissional para quem dela usufrui nos dias atuais, faz-se presente o papel contributivo dos professores que na EPT atuam. Considerando que o histórico da formação de professores para a EPT também teve seu marco inicial pautado por uma certa descredito social e ao longo da história recebeu maior comprometimento e incentivo por parte do Governo, visualiza-se um grande compromisso do profissional da educação consciente com o seu papel de educador na formação de um aluno não apenas a servir como mão-de-obra qualificada para o mercado de trabalho, mas também, como um cidadão crítico.

Essa preocupação com o tema da formação de professores para a EPT também perpassa a esfera acadêmica, onde, através de pesquisas investigativas, registram-se os conflitos, desafios, possibilidades e contribuições para o caso da formação pedagógica para o EPT. Nesse sentido, a subseção seguinte apresentará os registros obtidos através de uma pesquisa no site do Banco de Tese da Capes com o objetivo de mapear trabalhos acadêmicos que concentram suas pesquisas na temática da formação pedagógica para a EPT.

Conforme expõe Pereira (2004, p. 03):

A questão da profissionalização docente é uma polêmica nas esferas educacionais no mundo. Seja como expressão de uma aspiração, como característica do ofício de ensinar ou como discussão sobre as especificidades ou limitações com que tal condição se dá nos docentes, o tema do profissionalismo está presente nas expressões dos próprios docentes.

Notoriamente, a preocupação dos professores com a sua atuação nessa modalidade de ensino é um assunto que se faz necessário e emergencial, uma vez que a qualificação pedagógica contribui para intensificar o debate sobre a formação de professores para o serviço.

Conforme essa pesquisa registou em vários momentos de sua posição crítica, pesquisas acadêmicas envolvendo a formação do professor é um assunto sempre pertinente, pois, estimula a reflexão dos sujeitos pesquisadores para promoverem uma educação cada vez melhor. 


\section{A EDUCAÇÃO PROFISSIONAL BRASILEIRA E SEUS PROFESSORES: DESAFIOS A SEREM SUPERADOS}

Pesquisas sobre a formação do professor são sempre importantes, pois, é uma temática da qual, incansavelmente, a teoria se apresenta em descompasso com a prática, acarretando, assim, como aponta Nono (2011, p.17) em um "choque de realidade".

Nesse escopo, situar pesquisas com o foco na formação dos professores para a Educação Profissional Técnica (EPT), manifesta-se um assunto de também grande importância, uma vez que nesse espaço da formação docente, o que se observa é uma grande discrepância entre as relações políticas, teóricas e pedagógicas (ABREU, 2009).

Inicialmente, a questão problemática sobre a formação docente para o exercício na modalidade da EPT não é distinta dos problemas que acarretam os demais professores da educação básica brasileira; existe uma distância entre o que a universidade oferece e a realidade que espera do futuro professor (ABREU, 2009). No entanto, há um ponto diferencial e agravante no que tange a formação do professor para a EPT. De acordo com Abreu (2009), a universidade não prepara o docente para atuar como professor na modalidade da EPT e, na verdade, a universidade não prepara o professor para atuar como professor fora do Ensino Fundamental e Médio brasileiro. Sobre esse assunto, Oliveira Junior (2008 p.72) complementa expondo que

\footnotetext{
um dos maiores problemas relacionado com a formação de professores em geral e que ficou mais evidenciado nas tentativas de formação de professores para o ensino técnico é que as Universidades têm dificuldades intrínsecas para lidar com essa questão. Nas licenciaturas o que se ensina basicamente é a História da Educação [...] poucas vezes se discute o aqui e o agora. Poucas vezes se discute o real e o concreto, a escola da realidade e o que o professor irá encontrar.
}

Assim, registra-se o papel importante que incumbe às universidades no tocante a formação dos professores. De acordo com Valezi e Cox (2011), o docente que se depara com a missão de atuar em contexto de EPT, muitas vezes, enfrenta uma forte inquietação: como ser professor na educação profissional?

Essa dúvida é devida à formação do professor que desde o início do curso de licenciatura foi orientado a atuar em escolas de ensino fundamental e médio. Nesse prisma "os professores sentem-se desafiados a reorganizar suas práticas pedagógicas para atender efetivamente às novas demandas de aprendizagem nos cursos de formação profissional" (VALEZI, 2009 p.200) uma vez que durante a formação universitária não houve um momento didático voltado para essa modalidade do ensino.

Machado (2008, p.15) expõe que o universo acadêmico das licenciaturas é o mais caracterizado na formação docente para o serviço na EPT, pois, conforme a autora, as licenciaturas são um espaço 
privilegiado da formação docente inicial e pelo importante papel que podem ter na profissionalização docente, para o desenvolvimento de pedagogias apropriadas às especificidades da educação profissional, o intercâmbio de experiências no campo da educação profissional, o desenvolvimento da reflexão pedagógica sobre a prática docente nesta área, o fortalecimento do elo entre ensino-pesquisa-extensão, pensar a profissão, as relações de trabalho e de poder nas instituições escolares, a responsabilidade dos professores, etc.

Embora a explanação feita pela autora faça referência aos professores formados em licenciaturas, sabemos que na modalidade da EPT não atuam apenas docentes licenciados. E isso, também se apresenta como um ponto desafiador para o professor. Como já citado nesta pesquisa, em um dado momento da legislação nacional, houve um momento de cobrança para que os professores em atuação na EPT fossem licenciados ou professores formados por treinamento em serviço ( $\$ 4^{\circ}$ do Art. 87 da Lei Federal 9394/96 e ao Parecer CNE/CP 07/2009). No entanto, essa cobrança foi revogada a parir da Lei $\mathrm{n}^{\circ} 12.796 / 2013$.

Dessa forma, Abreu (2009) expõe que os professores atuantes na modalidade de ensino da EPT que não possuem uma formação pedagógica para o magistério passam pelas mesmas dificuldades na prática de suas aulas. Essas dificuldades estão mais a nível da didática em sala de aula, pois, não havendo uma disciplina voltada à ação da prática em contexto de sala de aula, muitas vezes, esses profissionais (bacharéis) não sabem como transpor seus conhecimentos práticos para uma explicação teórica.

Em face ao exposto, Machado (2008, p.14) expõe que "a carência de pessoal docente qualificado tem se constituído num dos pontos nevrálgicos mais importantes que estrangulam a expansão da educação profissional no país”. Abreu (2009) complementa essa posição defendendo a ideia de que há uma urgente necessidade de uma formação de professores melhores preparados para a atuação na EPT, uma formação que vá além do improviso em sala de aula, uma formação que integre a teoria com a prática real.

Sobre o ponto da qualificação do professor e do déficit que os cursos de formação apresentam, Imbernón (2009) expõe que, por mais que ainda esteja a passos lentos e tímido, o processo de formação de professores no Brasil acusa certo avanço e o que comprova essa afirmação são os inúmeros registros acadêmicos com pesquisas envolvendo a temática da formação do professor.

Sob essa percepção, Machado (2008) advoga que no momento em que uma política melhor definida sobre o preparo dos professores da EPT que atenda às necessidades práticas, será, certamente, um grande estímulo para a superação da atual debilidade teórica e prática deste campo educacional com relação aos aspectos pedagógicos e didáticos.

Pereira (2004) complementa a posição da autora mencionando que no momento em que a educação brasileira estiver estruturada em um currículo de formação de professores que articule a teoria e a prática, o científico e o tecnológico, com conhecimentos que oportunizem ao 
aluno atuar no mundo do trabalho em constante mudança, buscando a autonomia e desenvolvendo a criticidade e o investigativo, será o ponto chave para uma formação mais prática e menos traumática.

Complementando, ainda no contexto de superar os desafios na formação de professores, Leffa (2001, p.03) aponta que um dos grandes desafios recorrentes nas estruturas curriculares de preparação de professores é saber distinguir o que é formação do que é treinamento. Para o autor, formação é tudo aquilo que

busca a reflexão e o motivo por que uma ação é feita da maneira que é feita. Há, assim, uma preocupação com o embasamento teórico que subjaz à atividade do professor. Enquanto que o treinamento limita-se ao aqui e agora, a formação olha além.

Já treinamento define-se como "o ensino de técnicas e estratégias de ensino que o professor deve dominar e reproduzir mecanicamente, sem qualquer preocupação com sua fundamentação teórica" (LEFFA, 2001, p. 02).

Em suma, um professor treinado é um docente robotizado, pois, reproduz mecanicamente tudo aquilo que aprendeu (ou diz que aprendeu) de uma maneira rígida e sistemática. Sem chances de mudança. Um professor formado é um docente que recebeu a base da reflexão em sua construção profissional. Ele não reproduz de uma maneira metódica tudo o que diz ter aprendido. Um professor formado sabe ponderar o que deve ser ensinado, onde ensinado e para quem deve ser ensinado. A fim de ilustrar melhor a imagem do professor treinado e do professor formado, Leffa construiu o diagrama apresentado na Figura 01:

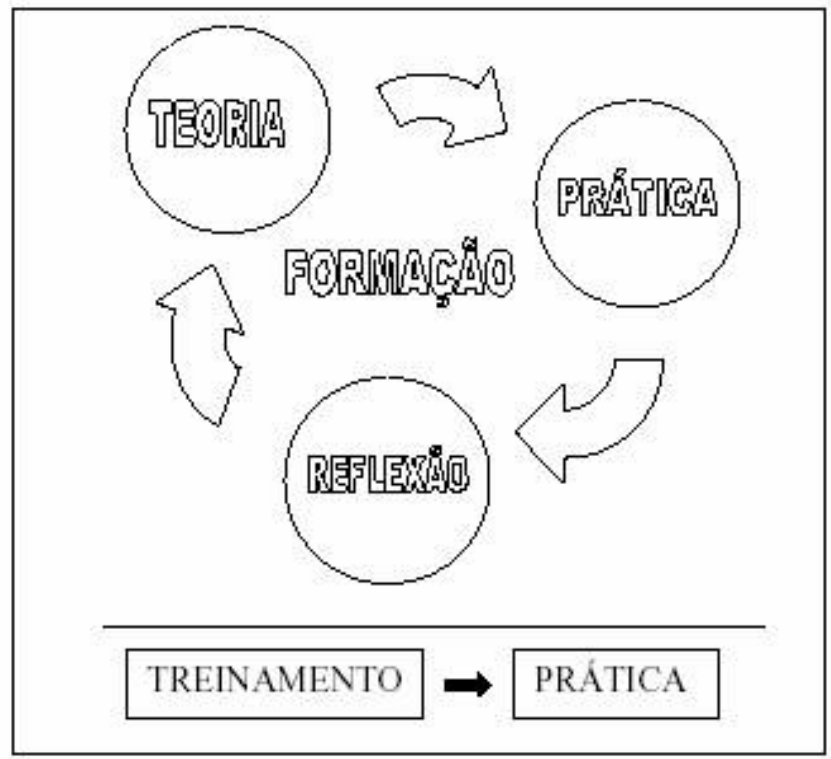

\section{Figura 1: Diferença entre formação e treinamento.}

Fonte: LEFFA, V. J. Aspectos políticos da formação do professor de línguas estrangeiras. In: LEFFA, V. J. (Org.). O professor de línguas estrangeiras; construindo a profissão. Pelotas, 2001, v. 1, p. 333-355. 
Na Figura 1, apresenta-se a ideia de que um professor formado possui uma linha cíclica de seu raciocínio. Ele sabe administrar as adversidades e complexidades que a sua formação venha a sofrer. Ele é um profissional capaz de administrar situações problemas. Já, o professor treinado, possui uma linha retilínea de raciocínio,

serial e seqüencial, onde não há retorno; inicia e termina com a prática. [...] $\mathrm{O}$ treinamento tem um começo, um meio e um fim. A formação, não. Ela é contínua. Um professor, que trabalha com um produto extremamente perecível como o conhecimento, tem a obrigação de estar sempre atualizado. (LEFFA, 2001, p.03-04)

Por fim, é perceptível que o assunto da formação de professores é uma temática sempre polêmica e carecida de constantes informações, pois, abordar questões sobre práticas pedagógicas sempre desestabilizam, provocam inseguranças, medos e resistência a encarar o novo. Nesse cenário, a formação do professor para o serviço na EPT ainda demonstra um despreparo maior, pois, muitos docentes saem de uma formação inicial sem a noção do que é a EPT (ABREU, 2009). Indo além, alguns professores até desconhecem a existência dessa modalidade de ensino brasileiro. Assim, fomentar mais pesquisas, incentivar a formação continuada e cobrar dos órgãos políticos nacionais melhorias no setor da educação brasileira, ainda são os melhores investimentos a favor dessa temática.

\section{CONSIDERAÇÕES FINAIS}

Pesquisas sobre formação de professores são sempre importantes, pois, é uma temática da qual, incansavelmente, a teoria se apresenta em descompasso com a prática, acarretando, assim, em um "choque de realidade" (NONO, 2011, p.17). Nesse segmento, fomentar investigações em prol de melhorias, sejam elas para os próprios professores, ou, sejam melhorias para o nosso sistema educacional, são sempre necessárias.

$\mathrm{Na}$ apresentação desta pesquisa sobre a temática da formação do professor para o serviço na EPT brasileira, percebe-se que a trajetória da docência nessa modalidade de ensino brasileiro passou por desafios ainda em fase de superações. De acordo com os trabalhos consultados, foi possível perceber que a docência na EPT, inicialmente marcada por um forte contingente de profissionais de áreas distintas e sem a qualificação pedagógica necessária para a atuação nesta modalidade, e que com a evolução dessa modalidade de ensino no Brasil, a EPT brasileira, a partir da LDB e a Lei $\mathrm{n}^{\circ} 5.692 / 61$, vem procurando estabelecer debates sobre a atuação do docente em serviço nessa modalidade. 
O papel social que desempenha um professor para formar cidadãos qualificados para o exercício de suas atribuições profissionais no mercado de trabalho é de suma importância. Entretanto, para que esse docente seja capaz de abordar questões profícuas na formação de um cidadão, deve-se reconhecer que ele próprio deva possuir uma formação de qualidade.

Sobre essa questão, Carvalho e Souza (2014) expõe que esses debates sobre a formação do professor em serviço na EPT têm levantado posições acadêmicas na área da educação, em investigações nessa temática, pois, como uma modalidade crescente no cenário educativo brasileiro, é mister a necessidade de investir maiores debates sobre o assunto do docente e a EPT. Esses debates, porém, não devem ser apenas de base acadêmica. Eles têm que partir também de uma ordem política, na qual os atores envolvidos se engajem em um plano de atualização - e formação - pedagógica para o efetivo serviço docente na EPT.

Por fim, é perceptível que o assunto da formação de professores é uma temática sempre polêmica e carecida de constantes informações, pois, abordar questões sobre práticas pedagógicas sempre desestabilizam, provocam inseguranças, medos e resistência a encarar o novo.

\section{REFERÊNCIAS}

ABREU, G.R. Ressignificação da formação do professor de ensino técnico-profissional: por uma prática reflexiva na reconstrução de sua identidade. RPD - Revista Profissão Docente, Uberaba, v.9, n. 21, p. 114-132, jan/jul. 2009.

BORGES, S.M. Possíveis contribuições da psicologia à educação profissional tecnológica: uma análise comparativa de grades curriculares. Santa Maria: 65f. 2013. Monografia (Especialização) - Celer Faculdades.

BRASIL, Ministério da Educação. Lei Federal $n^{\circ}$ 9.394, de 20 de dezembro de 1996. Estabelece as diretrizes e base da educação nacional - LDB. Disponível em: www.planalto.gov.br. Acesso em: 10 abril 2015.

Lei $n^{0}$ 6.545, de 30 de junho de 1978. Dispõe sobre a transformação das Escolas Técnicas Federais de Minas Gerais, do Paraná e Celso Suckow da Fonseca em Centros Federais de Educação Tecnológica e dá outras providências. Disponível em http://www.planalto.gov.br/ccivil_03/leis/L6545.htm. Acesso em 15 maio 2015.

Lei $n^{0}$ 12.513, de 26 de outubro de 2011. Institui o Programa Nacional de Acesso ao

Ensino Técnico e Emprego (Pronatec). Disponível em http://www.planalto.gov.br/ ccivil_03/_ato2011-2014/2011/lei/112513.htm. Acesso em 15 maio 2015.

O surgimento das escolas técnicas. Disponível em: http://www.brasil.gov.br/ educacao/2011/10/surgimento-das-escolas-tecnicas. Acesso em 18 maio 2015.

Linguagens - Revista de Letras, Artes e Comunicação ISSN 1981-9943 Blumenau, v. 11, n. 1, p. 357-374, jan./abr. 2017 
Catálogo Nacional de Cursos Técnicos. Disponível em: http://pronatec.mec.gov.br/ cnct/perguntas_frequentes.php. Acesso em 05 junho 2015.

Parecer CNE/CEB No: 11/2008. Proposta de instituição do Catálogo Nacional de Cursos Técnicos de Nível Médio. Disponível em http://portal.mec.gov.br/ setec/arquivos/pdf/pceb011_08.pdf. Acesso em 05 junho 2015.

Parecer CNE/CEB No 16/99. Trata das Diretrizes Curriculares Nacionais para a Educação Profissional de Nível Técnico. Disponível em http://portal.mec.gov.br/ setec/arquivos/pdf_legislacao/tecnico/legisla_tecnico_parecer1699.pdf. Acesso em 05 junho 2015.

CELANI, M.A.A. Prefácio. In: GIL,G.;VIEIRA-ABRAHÃO,M.H. Educação de professores de línguas: os desafios do formador. Campinas, SP: Pontes Editores, 2008.

CARVALHO, O.F; SOUZA, F.H.M. Formação do docente da educação profissional e tecnológica no Brasil: um diálogo com as faculdades de educação e o curso de pedagogia. Educ. soc. Campinas, v.35, nº 128, p.629-996, jul-set 2014.

IMBERNÓN, F. Formação Permanente do Professor: Novas Tendências. São Paulo: Cortez, 2009.

Formação Docente e Profissional: Formar-se para a mudança e a incerteza. São Paulo: Cortez, 2011.

KUNZE, N.C. O surgimento da rede federal de educação profissional nos primórdios do regime republicano brasileiro in Revista Brasileira da Educação Profissional e Tecnológica /Ministério da Educação, Secretaria de Educação Profissional e Tecnológica. v. 2, n. 2, (nov. 2009 - ). - Brasília: MEC, SETEC, 2009.

LEFFA, V. J. Aspectos políticos da formação do professor de línguas estrangeiras. In: LEFFA, Vilson J. (Org.). O professor de línguas estrangeiras; construindo a profissão. Pelotas, 2001, v. 1, p. 333-355.

MACHADO, L.R.S. Diferenciais inovadores na formação de professores para a educação profissional. In Revista Brasileira da Educação Profissional e Tecnológica. V. 1, n. 1Brasília: MEC, SETEC, 2008. Disponível em http://portal.mec.gov.br/setec/arquivos/ pdf3/rev_brasileira.pdf. Acesso em agosto de 2015.

MAGALHÃES, F.P. Gêneros discursivos da esfera empresarial no ensino da educação profissional: reflexões, análises e possibilidades. Pelotas: 358f. 2011 Dissertação (Mestrado) Pontifícia Universidade Católica de São Paulo. Universidade Católica de Pelotas.

NETO, A.C.S. Da Escola de Aprendizes ao Instituto Federal de Sergipe: 1909 - 2009 in Revista Brasileira da Educação Profissional e Tecnológica /Ministério da Educação, Secretaria de Educação Profissional e Tecnológica. v. 2, n. 2, (nov. 2009 - ). - Brasília: MEC, SETEC, 2009.

NONO, M.A. Professores iniciantes. O papel da escola em sua formação. Porto Alegre: Mediações, 2011. 
OLIVEIRA JUNIOR, Waldemar. A formação do professor para a educação profissional de nível médio: Tensões e (in)tenções. 2008. 127f. Dissertação (Mestrado em Educação) - Curso de pós-graduação em Educação, Universidade Católica de Santos, Santos - SP, 2008.

PEREIRA, L.A.C. A formação de professores e a capacitação de trabalhadores da educação profissional e tecnológica. Portal MEC, 2004. Disponível em http://portal.mec.gov.br/ setec/arquivos/pdf/tema5b.pdf. Acesso em 20 maio 2015.

VALEZI, Sueli Correia Lemes; COX, Maria Inês Pagliarini. A língua portuguesa no ensino técnico-profissionalizante: a hegemonia da concepção instrumental. Polifonia, Cuiabá, MT, v.18, n.23, p.147-162, jan./jun., 2011.

VALEZI, Sueli Correia Lemes. Ensino de línguas na educação profissional: os conflitos históricos e os desafios em sala de aula. Polifonia, Cuiabá EDUFMT No 17 P. 189-202, 2009. Disponível em: http://cpd1.ufmt.br/meel/arquivos/artigos/314.pdf. Acesso em 06 set. 2015. 